\title{
BMJ Open Impact of low and no alcohol beers on purchases of alcohol: interrupted time series analysis of British household shopping data, 2015-2018
}

\author{
Peter Anderson (D) , ${ }^{1,2}$ Eva Jané Llopis, ${ }^{3}$ Amy O’Donnell (D) , ${ }^{2}$ Jakob Manthey (D) ,4 \\ Jürgen Rehm ${ }^{5}$
}

To cite: Anderson $P$, Jané Llopis E, O'Donnell A, et al. Impact of low and no alcohol beers on purchases of alcohol: interrupted time series analysis of British household shopping data, 2015-2018. BMJ Open 2020;10:e036371. doi:10.1136/ bmjopen-2019-036371

- Prepublication history and additional material for this paper are available online. To view these files, please visit the journal online (http://dx.doi. org/10.1136/bmjopen-2019036371).

Received 14 December 2019 Revised 02 April 2020 Accepted 29 June 2020

Check for updates

(c) Author(s) (or their employer(s)) 2020. Re-use permitted under CC BY-NC. No commercial re-use. See rights and permissions. Published by BMJ.

${ }^{1}$ CAPHRI Care and Public Health Research Institute, Maastricht University, Maastricht, The Netherlands

${ }^{2}$ Population Health Sciences Institute, Newcastle University, Newcastle upon Tyne, UK

${ }^{3}$ ESADE Business School, Ramon Llull University, Barcelona, Spain

${ }^{4}$ Technische Universitat Dresden, Dresden, Germany

${ }^{5}$ Campbell Family Mental Health Research Institute, Centre for Addiction and Mental Health, Toronto, Ontario, Canada

Correspondence to Dr Jakob Manthey; jakob.manthey@tu-dresden.de

\section{ABSTRACT}

Objective To assess the impact of new low and no alcohol beers and reformulated beers in Great Britain on household purchases of grams of alcohol.

Design Interrupted time series analysis.

Setting Purchase data from Kantar Worldpanel's household shopping panel for 2015-2018.

Participants 64286 British households.

Interventions Introduction of new no and low alcohol beers during 2017-2018 and reformulation of existing beers to contain less alcohol during 2018.

Main outcome measures Average alcoholic strength of beer and number of grams of alcohol purchased by households.

Results As assessed by British household purchase data, 46 new low and no alcohol beer products were introduced during 2015-2018, with a step-jump in volume purchased occurring at the beginning of March 2017 (event 1). During 2015-2018, 33 beer products were reformulated to contain less alcohol, with a step-jump in volume purchased occurring during mid-March 2018 (event 2). Interrupted time series analyses found a combined associated impact of both events with relative reductions of alcohol by volume of beer between $1.2 \%$ and $2.3 \%$; purchases of grams of alcohol within beer between $7.1 \%$ and $10.2 \%$; and purchases of grams of alcohol as a whole between $2.6 \%$ and $3.9 \%$. The reductions were greater for reformulation than for the introduction of new low and no alcohol products. Reductions were independently higher for younger age groups of shoppers and for households that bought the most alcohol.

Conclusions Even though the events were associated with significant beneficial changes, the volume of purchases of new low and no alcohol beer products $(2.6 \%$ of the volume of all beers purchased during 2018) and of new reformulated beer products ( $6.9 \%$ of the volume of all beers purchased during 2018) was very small. This indicates that there are future opportunities to increase the volume of such products so as to reduce the harm done by alcohol.

\section{INTRODUCTION}

Alcohol use is a leading risk factor for ill health and premature death. ${ }^{1-3}$ There is a global target to reduce the harmful use of
Strengths and limitations of this study

- The study uses a large commercial data set of more than 3.3 million separate alcohol purchases from more than 64000 British households.

- The study uses objective purchase data obtained from scanned product barcodes.

- The study uses aggregated weekly data over 208 weeks.

- The study only captures off-trade purchases of alcohol and not on-trade purchases.

- The study analyses purchase data rather than consumption data.

alcohol by $10 \%$ between 2010 and 2025, with a main indicator of adult alcohol per-capita consumption. ${ }^{4}$ Recent analyses, however, indicate that, overall, the target will not be achieved. ${ }^{5}$

Thus, there is a need to step up action by core stakeholders, including governments and the private sector. For the private sector, the alcohol industry has a responsibility to reduce the harm done by its products. One way that this can be achieved is through actions to reduce the amount of alcohol its products contain. ${ }^{67}$

There are two main mechanisms through which reductions in the amount of alcohol in any product could reduce the harm done by alcohol. First is by current drinkers replacing standard alcoholic beverages with similar beverages of lower alcoholic strength, for example, consuming beer with $4 \%$ alcohol content instead of beer with $5 \%$ alcohol content, without increasing the volume of alcoholic beverages consumed. In this mechanism, drinkers, while not diminishing the experience of consuming alcohol, end up drinking less grams of ethanol, reducing their risks of the short-term and long-term harm done by alcohol. Second is by current 
drinkers switching to low and no alcohol alternatives for part of the time, thereby reducing the average amount of ethanol consumed. ${ }^{8}$ From a public health point of view, it is important that the reduction of alcohol concentration of alcoholic products is evaluated to demonstrate whether or not drinkers consume less grams of alcohol and thus incur less harm.

The model of changing the alcohol concentration of alcoholic products is similar to the model of salt reduction initiatives in which three approaches are identified ${ }^{9}$ : introduction of new products with less salt; product reformulation of existing products to contain less salt; and switching from one product with higher salt concentration to another product with lower salt concentration. British household purchase data indicate that almost all salt reductions have been achieved through product reformulation, rather than the introduction of new products with less salt. ${ }^{10}$

In this paper, we report on natural experiments in which we analyse British household panel shopping data for the years 2015-2018, covering 30000 households at any one time. We focus on new low and no alcohol beer products and on reformulation of existing beer products to contain less alcohol in them. Following Rehm et $a l^{8}{ }^{8}$ we ask two main questions within the British alcohol market:

- To what extent have there been purchases of new low and no alcohol beer products and reformulation of existing products to contain less alcohol, and have the purchases of such products differed by the sociodemographic characteristics of the households?

- To what extent have the purchases of new low and no alcohol beer products and reformulation of existing products to contain less alcohol been associated with changes in the purchases of grams of alcohol, and do such changes differ by the sociodemographic characteristics of the households?

\section{METHODS}

\section{Study design}

Plots of the volume of purchases of new no and low alcohol content beers and purchases of reformulated beers that contain less alcohol by British households in 2015-2018 indicated two large step-jumps: for new no and low alcohol content beers occurring at the beginning of March 2017 (event 1) and for reformulated beers occurring during mid-March 2018 (event 2) (see figure 1). We undertook interrupted time series analyses of the associated impacts of these two events on changes in the alcohol by volume (ABV\%) of purchased beer, on changes in grams of alcohol purchased within beer, and on changes in grams of alcohol purchased as a whole. We based our time series analyses ${ }^{112}$ on the recommendations of Beard $e t a l^{13}$ for addiction research. We used Autoregressive Integrated Moving Average (ARIMA) models, which treat dependent and independent variables as time series.

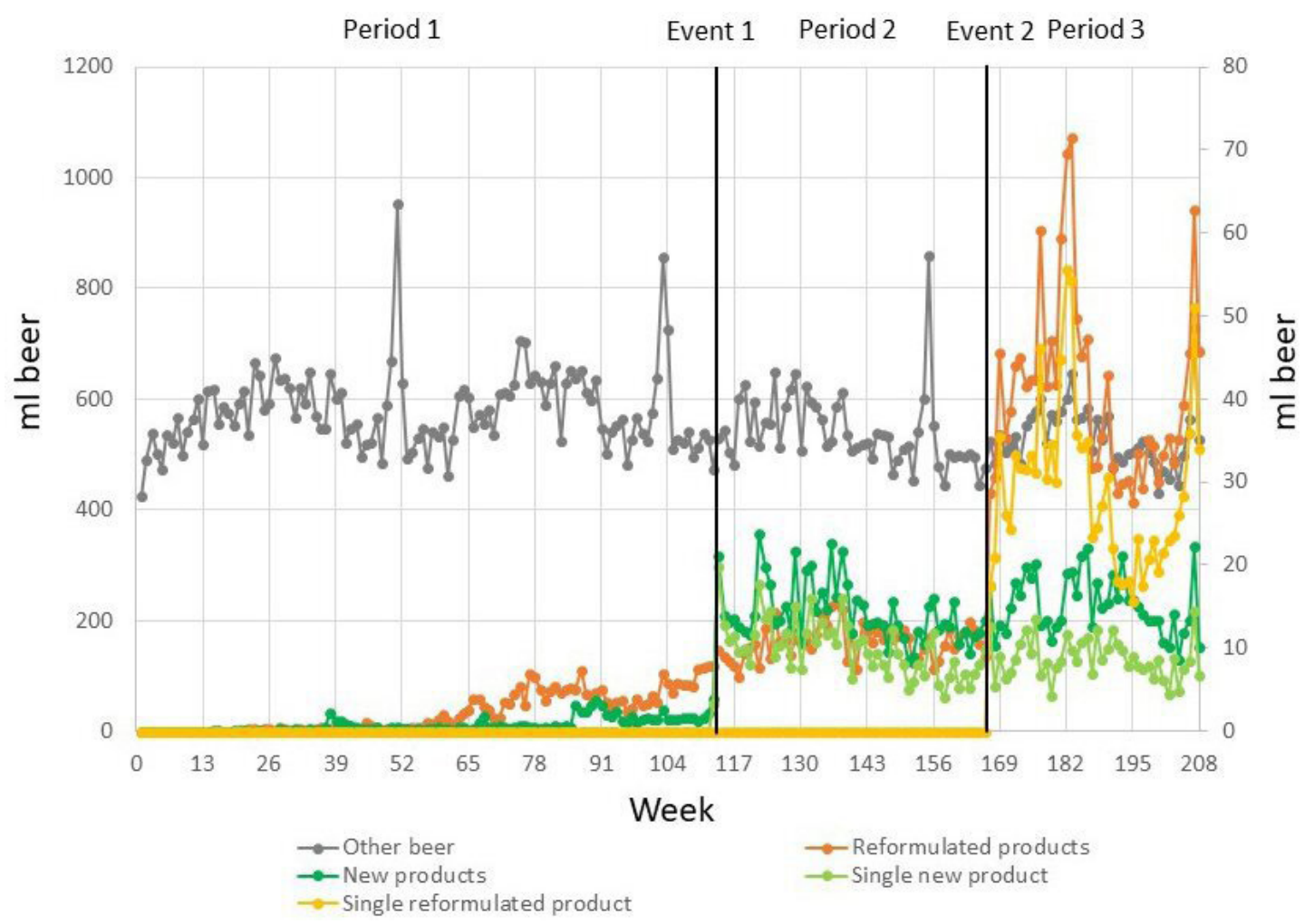

Figure 1 Volume $(\mathrm{mL})$ of beer purchased per adult per household per week across all households from week 1 (first week of 2015) to week 208 (last week of 2018) for new no and low alcohol beer (green, mL right secondary axis; light green, single new product), reformulated beer since time of reformulation (orange, $\mathrm{mL}$ right secondary axis; light orange, single reformulated product) and all other beers (grey, left primary axis). Vertical lines, events, dividing periods. 


\section{Data source}

Our data source is Kantar Worldpanel's (KWP) household shopping panel. KWP comprises approximately 30000 British households at any one time, recruited via stratified sampling, with targets set for region, household size, age of the main shopper and occupational group (see O'Donnell et al). ${ }^{14}$ Households record all purchases (from all store types) brought back into the home using barcode scanners. To be included in KWP's final data sets, households must meet quality control criteria (meeting thresholds for data recording and purchasing volume/spend (based on household size) every 4 weeks). Panellists also upload digital images of checkout receipts, which KWP uses to verify the accuracy of scanner data.

Households report the age of the main shopper, the number of adults in the household, income, social class and life stage of the household (eg, with young family, retired and so on). Based on UK Office for National Statistics classifications, truncated postcode data were used to group households into one of five areas based on 11 regions: South England (South West, London, South East and Eastern regions), Mid England (West Midlands and East Midlands regions), Wales, North England (North West, North East, and Yorkshire and Humber regions) and Scotland. The distributions of household sociodemographic characteristics were stable across each week for 2015-2018 (data not shown) and thus were not used as covariates in the analyses.

We obtained raw KWP data of all take-home purchases of alcohol products, including no and low alcohol products, for 4years, 2015-2018. Since only items purchased and taken home are recorded, only off-trade alcohol is included, that is, alcohol bought in supermarkets or other shops for consumption off the premises. Alcohol purchases are recorded daily. A detailed product description identifies the brand, the alcohol by volume (ABV), the volume of the purchase and the price paid. Volume was combined with ABV to calculate grams of alcohol purchased. To compare prices across all categories of products (beers, wines, spirits and so on), we calculated the price paid per gram of alcohol purchased, adjusting all products with an $\mathrm{ABV}$ of less than $3.5 \%$ to $3.5 \%$ to avoid a spurious high price for low alcohol products (see ref 14). For beer products, we calculated the price per millilitre of liquid paid.

From the ABV data, we identified purchases of new no or low beer products and purchases of reformulated existing beer products to a lower alcohol content. A new no or low alcohol beer product was defined as one with an ABV of $3.5 \%$ or less that was newly introduced, as evidenced by the purchase data, after week 13 of 2015, and that was still present in 2018. Forty-six products meeting this definition were identified between 2015 and 2018. Millilitres of purchased beer per adult per household per week are plotted in figure 1 . Of the 46 products, most had only a small number of purchases, with 41 having less than an average of one purchase a day across all households.
Product reformulation was defined as a brand whose ABV dropped by $0.11 \%$ or more during 2015-2018, with purchases still present during 2018. The drop of $0.11 \%$ was chosen as this represents the accepted margin of error allowed for ABV estimations, based on the mean ABV of purchased beer products in our sample. Millilitres of purchased beer per adult per household per week since reformulation are plotted in figure 1 . Given that the change in $\mathrm{ABV}$ occurred in an existing product with a natural lag due to shop shelf turnover, the average change in $\mathrm{ABV}$ of some reformulated products occurred over several weeks. For the date of the change, we took the week nearest to the midpoint in change of mean $\mathrm{ABV}$. For example, if the change in ABV started in week 160 and finished in week 174, we took week 167 as the date of the change. Of the 33 products, the vast majority had only a small number of purchases, with 24 having less than an average of one purchase a day across all households.

Visual inspection of figure 1 finds three natural periods, with one event (event 1 ) between periods 1 and 2 and a second event (event 2) between periods 2 and 3. Period 1 has no or very low levels of millilitres of no and low alcohol beer and of reformulated beer. Event 1 is a stepjump in purchases of no and low alcohol beer and a small increase in purchases of reformulated beer. Event 2, between periods 2 and 3, shows no change in purchases of no and low alcohol beer, but a step-jump in purchases of reformulated beer. One new product of $\mathrm{ABV}$ of $3.5 \%$ was responsible for $64 \%$ (95\% CI 62 to 67 ) of all purchased millilitres of new low and no alcohol beers during periods 2 and 3. One product whose ABV was reduced from $4.8 \%$ to $4.5 \%$ was responsible for $71 \%$ (95\% CI 69 to 73 ) of all postreformulation purchased millilitres during period 3 . The two step-jumps are the two events used in the interrupted time series analyses, separating period 1 from period 2, and period 2 from period 3 .

Figure 1 also illustrates the seasonal and non-seasonal changes in purchases of all other beers (majority of beer purchases, grey line, left primary axis), indicating the need to adjust for these in our time series analyses. There are peaks in purchases at the end of calendar years, associated with Christmas and New Year celebrations. There is also a smaller peak during mid-2018, probably associated with the 2018 football World Cup.

The dependent data were prepared for description and analysis as follows:

- For each of the 208 weeks, we calculated the mean ABV of all purchased beers.

- For each of the 208 weeks, we aggregated daily records of purchases in grams of alcohol in beer, and in all alcohol to weekly records of purchases in grams of alcohol across all households, adjusted for the number of adults in the household.

- We grouped households into the following:

- Five age groups of the age of the main shopper: 18-34, 35-44, 45-54, 55-64 and 65+ years (which correlated with life stage of the household). 
- Five groups based on purchased grams of alcohol per adult per household per week: $\leq 25,25-\leq 50$, $50-\leq 100,100-\leq 200$, and $>200$ grams of alcohol.

- Five social class groupings: AB, C1, C2, D and E, a system of demographic classification used in the UK, originally developed by the National Readership Survey to classify readers, with $A B$ including higher and intermediate managerial, administrative or professional workers, C1 supervisory or clerical and junior managerial, administrative or professional workers, C2 skilled manual workers, D semiskilled and unskilled manual workers, and $\mathrm{E}$ state pensioners, casual and lowest grade workers, and unemployed with state benefits only. ${ }^{15}$

- Five income groups per adult per household per year: $£ 0-7500,>7500-12500,>12500-15500,>17$ $500-25000$, and $>25000$.

- Five areas of Great Britain: South England, Mid England, Wales, North England and Scotland.

\section{Statistical analyses}

For each of our three continuous variables over time (mean ABV of beer products; mean grams of purchased alcohol within beer; and mean grams of all purchased alcohol), we seasonally adjusted the series with the Census Method I, ratio-to-moving-average method. ${ }^{16} 17$ For each adjusted variable, we examined the distribution visually and with $Q-Q$ plots and found all variables normally distributed. As recommended by a number of authors, ${ }^{13} 18$ we used a time series modeller function ${ }^{19}$ to estimate best fitting ARIMA models that specify degrees of differencing and transformations to ensure a stationary series and that specify autoregressive and moving average orders, thus eliminating the need to identify an appropriate model through trial and error. The model types, summarised in online supplemental table 1, identified no differencing terms, but some non-seasonal and seasonal autoregressive and moving average terms. We examined plots of the residual autocorrelation function summary statistics and residual partial autocorrelation function summary statistics of the modelled continuous variables and found low and non-significant smooth correlations across the range of lags (to lag 24), with no evidence of a non-stationary series and no evidence of autoregression (online supplemental figures 1-3).

In line with other published interrupted time series analyses, we included more than one event ${ }^{20}$ and slopes ${ }^{21}{ }^{22}$ in our ARIMA model. Our independent variables were slope 1 before event 1 , event 1 , slope 2 between events 1 and 2 , event 2 , and slope 3 after event 2 . The two event variables were entered as dummy variables coded with 0 for each week before the event and with 1 for each week from the event forwards. For the three slope changes variables, each week was coded with 0 if it fell outside the respective period and with increasing integers if it fell within the respective period.

We included one covariate, a composite measure of the price paid per quantity of alcohol and the household income adjusted for each adult in the household. Household income increased over time, and increases in price paid per quantity of alcohol purchased increased during the second 2 years of the study period, surpassing the income increases (online supplemental figure 4). We scaled the price and income variables to a per cent scale, based on the values of each at week 1 . The affordability variable for each week was then calculated as (scaled income/scaled price) $\times 100$, where a unit change is a $1 \%$ change in affordability. The affordability of both beer and all alcohol decreased during the second 2 years of the study period (online supplemental figure 5 ).

Thus, the three dependent variables in the ARIMA model were ABV\% of beer, grams of alcohol purchased within beer and grams of alcohol purchased as a whole (per adult per household per week). The independent variables were the intercept, the two events, the three slopes before and after the events, and affordability. We report unstandardised coefficients with $95 \%$ CIs and probability $(\mathrm{p})$ values.

We conducted a sensitivity analysis to test the assumption of the three distinct periods. Similar to Rehm et $a l^{20}$ we undertook the ARIMA regression models for each dependent variable on two subsets of the time series, namely only periods 1 and 2 , and only periods 2 and 3 .

A drawback of ARIMA models is their inability to assess moderation effects (eg, by household characteristics). Thus, as recommended by Beard $e t a l,{ }^{13}$ we repeated the ARIMA models for all three periods for each of the five separate groupings of households (by age of the main shopper, amount of alcohol purchased overall, class group, household income and area of Great Britain). Area of Great Britain included Scotland as one of the areas, allowing for us to account for the main policy change that occurred during the time period, the introduction of a minimum unit price in Scotland at week 174, beginning of May 2018. ${ }^{14}$ For the ARIMA models, as recommended by Beard et $a l,{ }^{13}$ we transformed the continuous variables into their z-scores and used the z-scores as the dependent variables, so that the results can be compared between groups in terms of SD, rather than original units. This allows us to compare the relative importance of the regression coefficients, and thus changes, across the characteristics of each of the household groupings and the household groupings themselves. For the five groupings, we report standardised coefficients with $95 \%$ CI.

All analyses were performed with SPSS V.25. ${ }^{19}$

\section{Patient and public involvement}

The research was done without public involvement. The public was not consulted to develop the research questions, nor was it involved in identifying the study design or outcomes. We did not invite the public to participate in the interpretation of results, nor in the writing or editing of this paper. There are no plans to directly involve the public in the dissemination of the research findings. 
Table 1 Mean weekly purchases of volume $(\mathrm{mL})$ of new low and no alcohol beer products, reformulated beer products (since time of reformulation), all other beer products, and all beer products (total) for the three periods

\begin{tabular}{|c|c|c|}
\hline Period & Product & Mean mL (95\% Cl) \\
\hline \multirow[t]{4}{*}{$\begin{array}{l}1 \text { (weeks } \\
1-112)\end{array}$} & $\begin{array}{l}\text { New low and no } \\
\text { alcohol beers }\end{array}$ & 0.7 (0.6 to 0.9$)$ \\
\hline & Reformulated beers & 2.1 (1.7 to 2.6$)$ \\
\hline & All other beers & 578.1 (565.9 to 592.2) \\
\hline & $\begin{array}{l}\text { All beer products } \\
\text { (total) }\end{array}$ & 581.0 (568.7 to 595.4) \\
\hline \multirow[t]{4}{*}{$\begin{array}{l}2 \text { (weeks } \\
113-166)\end{array}$} & $\begin{array}{l}\text { New low and no } \\
\text { alcohol beers }\end{array}$ & 14.1 (13.1 to 15.2$)$ \\
\hline & Reformulated beers & 10.7 (10.2 to 11.3$)$ \\
\hline & All other beers & 539.9 (522.8 to 558.8$)$ \\
\hline & $\begin{array}{l}\text { All beer products } \\
\text { (total) }\end{array}$ & 564.7 (547.0 to 584.0$)$ \\
\hline \multirow[t]{4}{*}{$\begin{array}{l}3 \text { (weeks } \\
167-208)\end{array}$} & $\begin{array}{l}\text { New low and no } \\
\text { alcohol beers }\end{array}$ & 15.2 (14.3 to 16.3 ) \\
\hline & Reformulated beers & 40.7 (37.6 to 44.1$)$ \\
\hline & All other beers & 532.0 (516.6 to 549.5$)$ \\
\hline & $\begin{array}{l}\text { All beer products } \\
\text { (total) }\end{array}$ & 588.0 (569.3 to 609.9) \\
\hline
\end{tabular}

\section{RESULTS}

Purchases of new low and no alcohol beer products and of reformulated beer products

Table 1 summarises the mean weekly purchases of volume of new low and no alcohol beer products, reformulated beer products, all other beers, and all beer products for the three periods illustrated in figure 1. Purchases of new low and no alcohol beer products were very low during period 1 , increased during period 2 and remained stable during period 3. Purchases of reformulated products were very low during period 1, increased during period 2 and increased substantially during period 3. During period 3, new low and no alcohol beer products were $2.6 \%$ of the volume of all beer products and reformulated beer products $6.9 \%$.

Online supplemental figure 6 plots the mean ABV (\%) for the new and reformulated products over time. The mean ABVs of both categories of products were relatively high to begin with, decreasing over time. In 2018, the mean $\mathrm{ABV}$ of new low and no alcohol beer products was $2.08 \%$ (95\% CI 1.99 to 2.16 ) and of reformulated beer $4.88 \%$ (95\% CI 4.83 to 4.93 ).

Figure 2A-E summarises the mean weekly purchases (per adult per household) of volume of new low and no alcohol beer products and reformulated beer products for the three periods defined in figure 1 by the sociodemographic characteristics of the households. The volume of purchases was considerably greater for both new and reformulated products during periods 2 and 3 the younger the age of the main shopper (figure 2A) and the higher the amount of overall alcohol purchased by households (expressed as purchased grams of alcohol) (figure 2B). That these are independent effects is indicated by the data in online supplemental table 2 . The mean purchase of grams of alcohol per adult per household per week increased progressively from $76.2 \mathrm{~g}(95 \% \mathrm{CI}$ 75.7 to 76.7 ) among the age group of the main household shopper of $18-34$ years, to $132.9 \mathrm{~g}$ (95\% CI 132.4 to 133.4) among those aged 65+ years. Volumes of purchases during periods 2 and 3 were a little higher in class groups $\mathrm{D}$ and $\mathrm{E}$ than in $\mathrm{AB}, \mathrm{C} 1$ and $\mathrm{C} 2$ (figure $2 \mathrm{C}$ ). For reformulated products, volume of purchases was a little higher in the higher income households (figure 2D). Volumes of purchases of new no and low alcohol products were higher in North England for periods 2 and 3 (figure 2E).

\section{Impact of new low and no alcohol products on purchases of grams of alcohol}

Figure 3 plots the seasonally adjusted dependent variables, with the predicted values derived from the ARIMA models of the impact of the two events, and table 2 displays the coefficients.

Following event 1 (the upward turn in purchased new low and no alcohol beer products), the previous significant upward slopes 1 for each of the three dependent variables plateaued: there was a slight decrease in slope 2 for mean $\mathrm{ABV}$ of beer, and there were flat slopes 2 for grams of alcohol purchased within beer and grams of alcohol purchased overall. Following event 2 (the upward turn in purchased reformulated beer), there were significant downward slopes 3 for all three dependent variables. The sizes of the downward slopes were larger for slope 3 (largely reformulated beer products) than for slope 2 (largely new low and no alcohol beers).

We estimated the overall impact of the introduction of new low and no alcohol beer products and reformulation of existing products on changes in the three dependent variables in two ways:

- Subtracting the predicted values at week 208 from the predicted values at week 112, a lower size estimate.

- Extrapolating a new predicted value at week 208 by continuing slope 1 through to week 208, and subtracting the original predicted value at week 208 from the extrapolated predictive value at week 208, a higher size estimate.

This resulted in an estimated overall impact of reduction of mean $\mathrm{ABV}(\%)$ of beer of between 0.052 (lower size estimate) and 0.107 (higher size estimate), a 1.2\%2.3\% relative drop; reduction of purchased grams of alcohol within beer (per adult per household per week) of between 1.4 and $2.1 \mathrm{~g}$, a $7.1 \%-10.2 \%$ drop; and reduction of purchased grams of alcohol overall (per adult per household per week) of between 2.8 and $4.2 \mathrm{~g}$, a $2.6 \%$ $3.9 \%$ drop.

The sensitivity analysis, repeating the ARIMA models for two separate time periods (only periods 1 and 2 and only periods 2 and 3 ), found similar sizes of coefficients, and strongly confirmed the greater downward slopes during period 3 than during period 2 (table 3 ). 

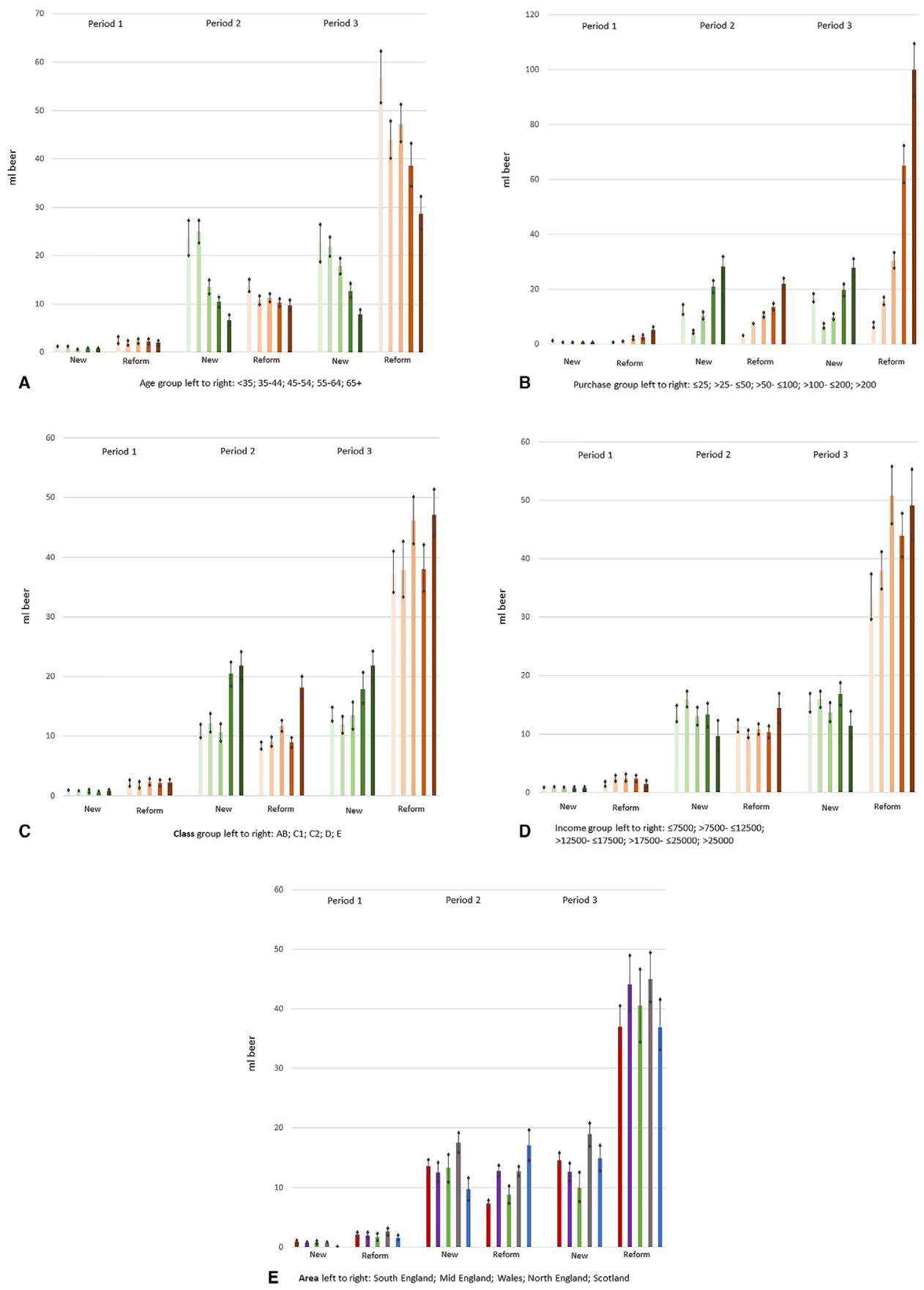

Figure 2 Purchases of new and reformulated beer products ( $\mathrm{mL}$ of beer) at each of the three periods by sociodemographic characteristics of households: age of the main shopper in years (A); number of grams of alcohol purchased overall per adult per household per week (B); class group (C); household income per adult per year (D); and area of Great Britain (E).

Figure 4A-E plots the fitted values for purchases of grams of alcohol within beer over time from the ARIMA models by household characteristics. The values are standardised coefficients, reporting changes in $\mathrm{SD}$, and thus on a common scale for all outputs, with the coefficients tabulated for all three dependent variables in online supplemental table 3A-E. Drops in purchases of grams of alcohol within beer were greater the younger the age of the main shopper (figure 4A) and were greater the higher the amount of overall alcohol purchased by households (expressed as purchased grams of alcohol) (figure 4B). That these are independent effects is again indicated by the data that the number of grams of alcohol purchased by households increased with increasing age of the main shopper (online supplemental table 2). Drops in purchases of grams of alcohol within beer did not substantially differ by social class groups (figure 4C) and by household income (figure 4D). Drops in purchases of alcohol within beer occurred in all five areas of Great Britain, although were larger in Scotland, a likely reflection of the introduction of minimum unit price during week 174 (figure 4E). 

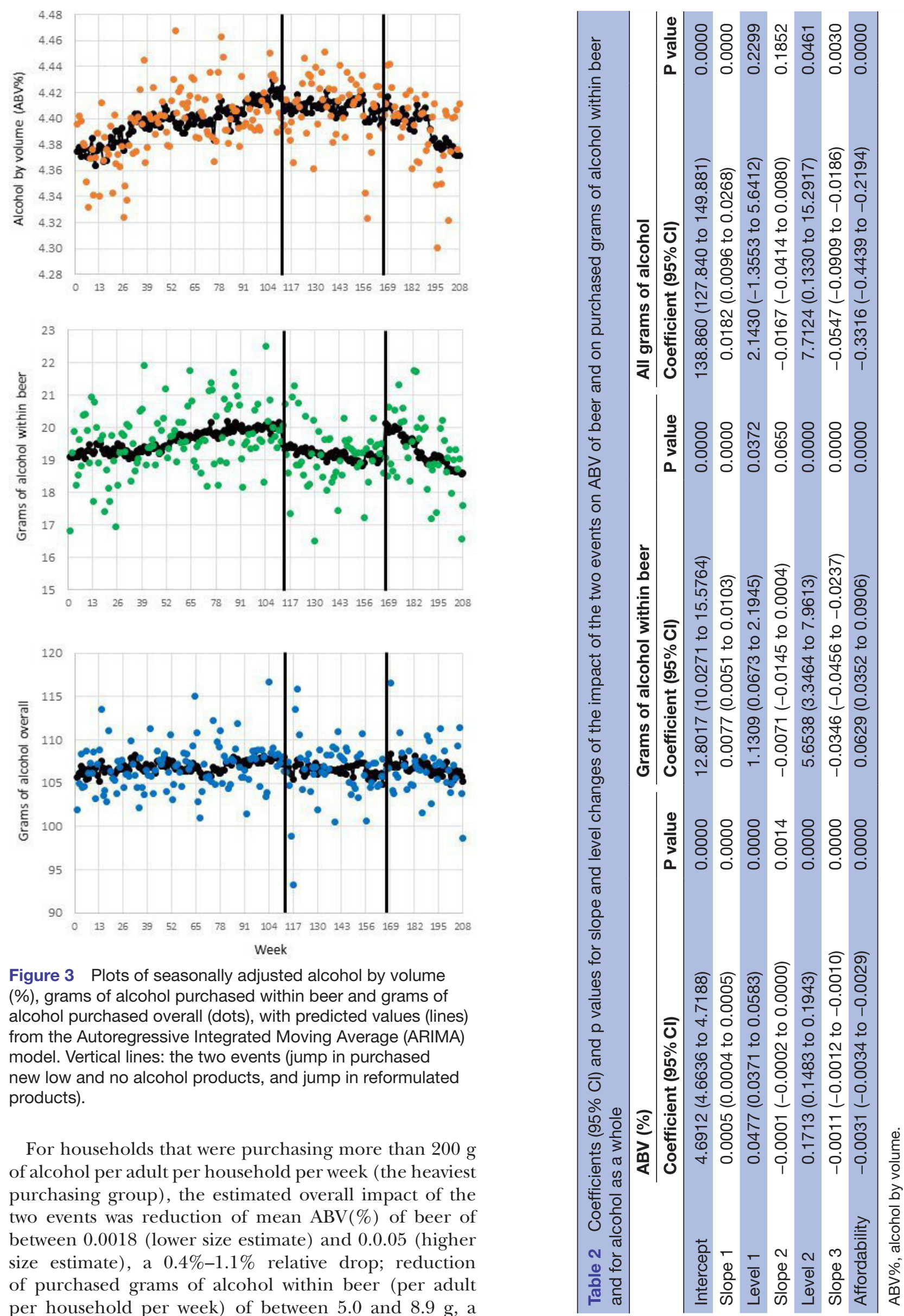
Table 3 Sensitivity analysis: coefficients and p values for two separate analyses, periods 1 and 2 and periods 2 and 3

\begin{tabular}{|c|c|c|c|c|}
\hline & \multicolumn{2}{|l|}{ Periods 1 and 2} & \multicolumn{2}{|l|}{ Periods 2 and 3} \\
\hline & Coefficient & $P$ value & Coefficient & $P$ value \\
\hline \multicolumn{5}{|c|}{ Alcohol by volume (\%) of beer } \\
\hline First slope & 0.0005 (0.0005 to 0.0005$)$ & 0.000 & $-0.0001(-0.0002$ to -0.0001$)$ & 0.000 \\
\hline Event & 0.0486 (0.0328 to 0.0644$)$ & 0.000 & 0.1702 (0.1583 to 0.1820$)$ & 0.000 \\
\hline \multicolumn{5}{|c|}{ Purchase grams of alcohol within beer } \\
\hline Intercept & 10.5313 (8.3448 to 12.7178$)$ & 0.000 & $14.6872(12.5802$ to 16.7943$)$ & 0.000 \\
\hline First slope & $0.0076(0.0058$ to 0.0093$)$ & 0.000 & $-0.0056(-0.0092$ to -0.0020$)$ & 0.002 \\
\hline Event & $0.9975(0.2772$ to 1.7177$)$ & 0.007 & 5.8706 (4.7517 to 6.9894$)$ & 0.000 \\
\hline Intercept & $130.839(119.141$ to 142.537$)$ & 0.000 & $180.884(173.432$ to 188.336$)$ & 0.000 \\
\hline First slope & 0.0167 (0.0085 to 0.0250$)$ & 0.000 & $-0.0196(-0.0302$ to -0.0090$)$ & 0.000 \\
\hline Event & $2.1522(-1.1968$ to 5.5011$)$ & 0.208 & 8.8731 (5.6206 to 12.1256$)$ & 0.000 \\
\hline Second slope & $-0.0155(-0.0392$ to 0.0082$)$ & 0.199 & $-0.0661(-0.0817$ to -0.0505$)$ & 0.000 \\
\hline Affordability & $-0.2503(-0.3695$ to -0.1312$)$ & 0.000 & $-0.7393(-0.8126$ to -0.6660$)$ & 0.000 \\
\hline
\end{tabular}

For periods 1 and 2: first slope=slope 1; event=level 1; second slope=slope 2. For periods 2 and 3: first slope=slope 2; event=level 2; second slope=slope 3 .

9.5\%-15.1\% drop; and reduction of purchased grams of alcohol overall (per adult per household per week) of between 3.0 and $9.8 \mathrm{~g}$, a $0.9 \%-2.8 \%$ drop.

\section{DISCUSSION}

We report natural experiments from Great Britain in which new low and no alcohol beer products were introduced and in which existing beer products were reformulated to contain less alcohol. We analysed British household panel shopping data for the years 2015-2018, covering 30000 households at any one time, with 3332140 separate alcohol purchases and 876484 separate beer purchases. ${ }^{14}$

We found evidence for purchases of new low and no alcohol beers and for purchases of reformulated existing beers to contain less alcohol in them between 2015 and 2018. For new low and no alcohol beer products, this was only present to a marked degree during 2017 and 2018, with no substantial increase in purchases in 2018 compared with 2017. For reformulated products, the change was only present to a marked degree during 2018. During 2018, new low and no alcohol beer products were responsible for only $2.6 \%$ of the purchased volume of all beer products, and reformulated beer products only $6.9 \%$ of the purchased volume of all beer products since the time of reformulation. For both cases, one product was responsible in each category for around two-thirds of all volumes of purchases. Trends in the ABV of the new and reformulated products indicate that new products were low rather than no alcohol products, and that reformulation occurred more in higher strength than in lower strength products (see online supplemental figure 6 ). The increase in purchases of both low and no alcohol products and of reformulated products was driven to a large extent independently by younger shoppers and by households that bought the most alcohol (expressed as grams). There was no evidence of systematic variation by indices of inequality, class group, household income or area of Great Britain (figure 2).

Despite the small changes in purchases, we found significant associations between both step-jump events, the introduction of new low and no alcohol products and the reformulation of existing products to contain less alcohol, and reductions in the mean $\mathrm{ABV}$ of beer and reductions in purchases of both grams of alcohol within beer and grams of alcohol as a whole. Both events led to an overall reduction in the ABV of beer of between $1.2 \%$ and $2.3 \%$; a reduction in the purchases of grams of alcohol within beer of between $7.1 \%$ and $10.2 \%$; and a reduction in the purchases of grams of alcohol as a whole of between $2.6 \%$ and $3.9 \%$. Associated reductions over time were greater for reformulation than for the introduction of new low and no alcohol products. Reductions in purchases of grams of alcohol within beer due to the events matched the distribution of purchases across the three periods by sociodemographic characteristics 

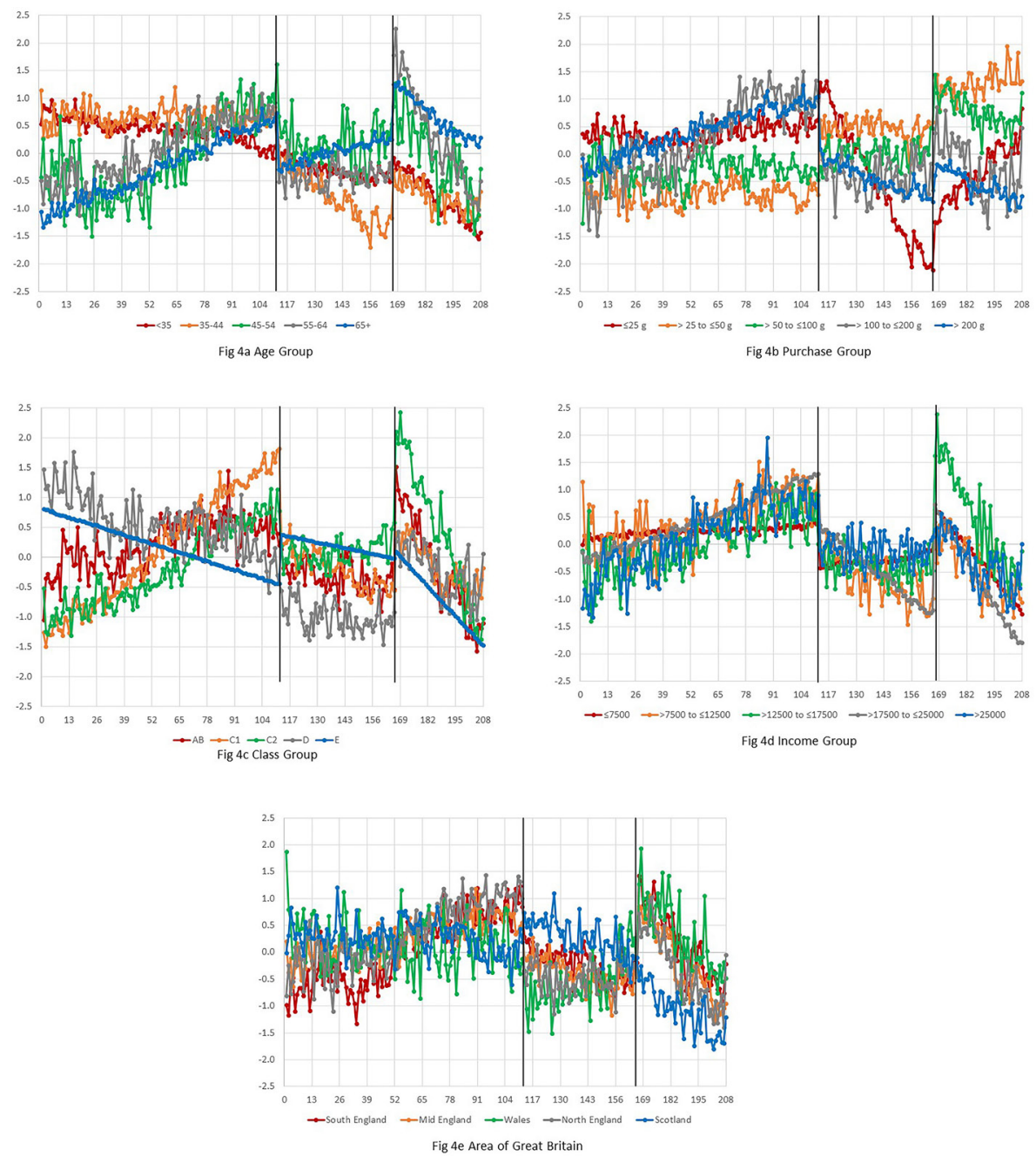

Figure 4 Plots of fitted values from Autoregressive Integrated Moving Average (ARIMA) models reporting standardised coefficients that are SDs, resulting in coefficients that are relative and all on the same scale by sociodemographic characteristics of households: age of main shopper in years (A); number of grams of alcohol purchased overall per adult per household per week (B); class group (C); household income per adult per year (D); and area of Great Britain (E) (see online supplemental table 1 for coefficients). Black vertical lines: timing of events.

summarised in figure 2. The reductions, summarised in figure 4 , were greater the younger the age of the shopper and greater in the households that purchased the higher number of grams of alcohol, both independent effects. That relative reductions are greater among higher purchasing households is of public health importance given that the same reduction in alcohol consumption among heavier drinkers brings greater health gain than among lighter drinkers. ${ }^{23}$ There was no evidence in terms of inequality in reductions, which did not differ substantially by class group, household income group or area of Great Britain other than Scotland. That reductions occurred across all five areas of Great Britain demonstrates that the associated reductions were independent of the introduction of minimum unit price in Scotland. Reductions, though, were greater in Scotland during period 3, coinciding with the introduction of minimum unit price. ${ }^{14}$

Given the potential impacts of reformulated beer products on reducing purchases of grams of alcohol, it is disappointing to note the low overall volumes of such purchased products, with $71 \%$ of postreformulation volume of purchases contributed by just one product alone. This indicates that there are large missed opportunities for beer producers as a whole to take responsibility for their products and to contribute to a reduction in the harmful use of alcohol. Our data suggest that, at least in the British market, this is likely best achieved through reformulation of existing regular strength beer products with high-volume-sales beer to contain less alcohol. 
Our study has several strengths. First, it uses a large commercial data set with more than 3.33 million separate alcohol purchases and 876000 separate beer purchases from more than 64000 British households, with objective purchase data obtained from scanned product barcodes. ${ }^{14}$ Second, although we are examining associations and cannot be certain of causal effects, the use of interrupted time series analysis represents a strong, appropriate method for the evaluation of natural experiments such as the introduction of new no and low alcohol beer products on public health relevant outcomes. ${ }^{14}$ Third, there was internal consistency in that the greatest impacts occurred among lower age shoppers and in households that purchased the greatest amount of alcohol, the two groups that had the higher purchases of new and reformulated products. Fourth, our analysis by area of Great Britain allowed us to account for the main alcohol policy change that occurred during the time frame, the introduction of minimum unit price in Scotland, May 2018, ${ }^{14}$ where we found an impact of the two events in areas of Great Britain other than Scotland.

Our study, though, has three main weaknesses. First, panel data may not capture all beer purchases. While most primary shopping is done by women, secondary top-up shopping, which is more likely done by men, may be less well recorded. ${ }^{24}$ Second, panel data may exclude certain segments of the population that are more likely to be heavy drinkers, such as homeless people, and may have lower representation of single adult households. ${ }^{14}$ Third, panel data only capture offtrade purchases, and not on-trade purchases ${ }^{20}$ with panel data being purchase and not actual consumption data. Over the 4-year period, 2015-2018 for Great Britain, off-trade purchases accounted for $69.4 \%$ of all alcohol purchases in 2015, increasing to $71.5 \%$ in 2018; for beer, the equivalent proportions were $50.1 \%-52.9 \% .^{25}$ Ideally, we would want similar analyses for all alcohol purchases, both off and on trade. Fourth, although we had a relatively large number of observations before and after the events, as indicated by the requirements of Beard et al, ${ }^{13}$ our overall time frame does not necessarily allow for analyses of durability and sustainability of the findings. Periods 2 and 3 following event 1 amounted to nearly two complete annual seasons of alcohol purchases, whereas period 3 following event 2 amounted to less than full one season. Ideally, changes should be studied over a longer time period, matching, for example, studies of salt reformulation that have examined changes in Britain over a 6 -year period. ${ }^{10}$ Despite these shortcomings, the findings, though, are consistent with the mechanisms that we previously identified. ${ }^{8}$

We are not aware of any similar large-scale natural experiments that have evaluated the impact of the introduction of new no and low alcohol products and of product reformulation on purchases of grams of alcohol. ${ }^{8}$ Although a Department of Health's interim evaluation of the UK alcohol industry's 'billion units pledge' suggested that the initiative had been a success, ${ }^{26}$ the methods have been strongly criticised, ${ }^{27}$ and there has been no further independent evaluation.

Outside of alcohol, there are parallel examples with salt reduction initiatives. ${ }^{9}$ For example, an analysis of salt reduction initiatives in the British market, using KWP data, found that the salt concentration (similar to $\mathrm{ABV}$ ) was $0.370 \mathrm{~g}$ per $100 \mathrm{~g}$ of food purchases in 2005 , reducing to $0.351 \mathrm{~g}$ per $100 \mathrm{~g}$ in 2011 , a $5.1 \%$ reduction over the 6 -year period. ${ }^{10}$ Our analysis found a $1.2 \%-2.3 \%$ reduction in the mean $\mathrm{ABV}$ of beer over a shorter 2-year period. For salt reduction initiatives, salt reduction was almost exclusively due to product reformulation of existing products, rather than the introduction of new products with less salt in them (Trieu et $a l$ )..$^{9}$ Our analyses found that whereas period 2 (largely the introduction of new products with less alcohol in them) led to a plateauing of the previous increases during period 1, period 3 (largely the reformulation of existing products to contain less alcohol in them) had significant downward slopes, suggesting that reformulation was having greater associated impacts in reducing the purchases of grams of alcohol than the introduction of new low and no alcohol beer products.

\section{CONCLUSION}

While the purchase data find the introduction of new low and no alcohol beers and reformulation of existing beer products to contain less alcohol in Great Britain during 2015-2018, the volume of changes has been small and dominated by just two products. Nevertheless, small though they are, these changes are associated with reductions in the mean ABV of beer and reductions in household purchases of grams of alcohol within beer and in purchases of grams of alcohol as a whole, with reductions greater in higher alcohol-purchasing households than in lower alcoholpurchasing households. Despite these changes, the data on small volumes of new and reformulated products indicate that the beer industry as a whole has, at least by the end of 2018 , yet to live up to its responsibilities to address its products in such ways so as to reduce the harm done by alcohol.

Twitter Jakob Manthey @MantheyJakob

Acknowledgements We thank Kantar Worldpanel for providing the raw data.

Contributors PA and A0'D obtained the data and managed the data set. PA, EJL, $A 0$ 'D, JM and JR collectively conceptualised the paper. PA did the first draft of the original paper. PA undertook the analyses, with input and advice from JM and JR. PA, EJL, AO'D, JM and JR refined the various versions of the paper and approved the final manuscript. JM, as the corresponding author, attests that all listed authors meet the authorship criteria and that no others meeting the criteria have been omitted. PA and AO'D are the guarantors.

Funding The authors have not declared a specific grant for this research from any funding agency in the public, commercial or not-for-profit sectors. 
Competing interests PA declares receipt of funds from AB InBev Foundation, outside of the submitted work. Kantar Worldpanel reviewed the method description as it describes the purchase data.

Patient consent for publication Not required.

Provenance and peer review Not commissioned; externally peer reviewed.

Data availability statement Kantar Worldpanel data cannot be shared due to licensing restrictions.

Supplemental material This content has been supplied by the author(s). It has not been vetted by BMJ Publishing Group Limited (BMJ) and may not have been peer-reviewed. Any opinions or recommendations discussed are solely those of the author(s) and are not endorsed by BMJ. BMJ disclaims all liability and responsibility arising from any reliance placed on the content. Where the content includes any translated material, BMJ does not warrant the accuracy and reliability of the translations (including but not limited to local regulations, clinical guidelines, terminology, drug names and drug dosages), and is not responsible for any error and/or omissions arising from translation and adaptation or otherwise.

Open access This is an open access article distributed in accordance with the Creative Commons Attribution Non Commercial (CC BY-NC 4.0) license, which permits others to distribute, remix, adapt, build upon this work non-commercially, and license their derivative works on different terms, provided the original work is properly cited, appropriate credit is given, any changes made indicated, and the use is non-commercial. See: http://creativecommons.org/licenses/by-nc/4.0/.

\section{ORCID iDs}

Peter Anderson http://orcid.org/0000-0003-4605-9828

Amy 0'Donnell http://orcid.org/0000-0003-4071-9434

Jakob Manthey http://orcid.org/0000-0003-1231-3760

\section{REFERENCES}

1 Rehm J, Gmel GE, Gmel G, et al. The relationship between different dimensions of alcohol use and the burden of disease-an update. Addiction 2017;112:968-1001.

2 GBD 2016 Alcohol Collaborators. Alcohol use and burden for 195 countries and territories, 1990-2016: a systematic analysis for the global burden of disease study 2016. Lancet 2018.

3 Wood AM, Kaptoge S, Butterworth AS, et al. Risk thresholds for alcohol consumption: combined analysis of individual-participant data for 599912 current drinkers in 83 prospective studies. Lancet 2018;391:1513-23.

4 Manthey J, Shield KD, Rylett M, et al. Global alcohol exposure between 1990 and 2017 and forecasts until 2030: a modelling study. Lancet 2019;393:2493-502.

5 World Health Organization. Global action plan for the prevention and control of NCDS 2013-2020. Geneva: World Health Organization, 2013.

6 World Health Organization. Global strategy to reduce the harmful use of alcohol. Geneva: World Health Organization, 2010.

7 OECD. Tackling harmful alcohol use. Paris: OECD Publishing, 2015.
8 Rehm J, Lachenmeier DW, Llopis EJ, et al. Evidence of reducing ethanol content in beverages to reduce harmful use of alcohol. Lancet Gastroenterol Hepatol 2016;1:78-83.

9 Trieu K, Neal B, Hawkes C, et al. Salt reduction Initiatives around the World - a systematic review of progress towards the global target. PLoS One 2015;10:e0130247.

10 Griffith R, O'Connell M, Smith K. The importance of product reformulation versus consumer choice in improving diet quality, IFS working papers, no. W14/15. London: Institute for Fiscal Studies, 2014.

11 Lopez Bernal J, Cummins S, Gasparrini A. The use of controls in interrupted time series studies of public health interventions. Int $J$ Epidemiol 2018;47:2082-93.

12 Bhaskaran K, Gasparrini A, Hajat S, et al. Time series regression studies in environmental epidemiology. Int $\mathrm{J}$ Epidemiol 2013;42:1187-95.

13 Beard E, Marsden J, Brown J, et al. Understanding and using time series analyses in addiction research. Addiction 2019;114:1866-84.

14 O’Donnell A, Anderson P, Jané-Llopis E, et al. Immediate impact of minimum unit pricing on alcohol purchases in Scotland: controlled interrupted time series analysis for 2015-18. BMJ 2019;366:I5274.

15 National Readership Survey. Social grade London: national readership survey, 2019. Available: http://www.nrs.co.uk/ nrs-print/lifestyle-andclassification-data/social-grade/ [Accessed 10 Jul 2019].

16 Makridakis S, Wheelwright SC, McGee VE. Forecasting: methods and applications. New York: John Wiley and Sons, 1983.

17 McLaughlin RL. Forecasting techniques for decision making. Rockville, MD: Control Data Management Institute, 1984.

18 Jebb AT, Tay L, Wang W, et al. Time series analysis for psychological research: examining and forecasting change. Front Psychol 2015;6:727.

19 International Business Machines. Ibm SPSS statistics for windows, version 25.0. Armonk, NY: IBM Corp, 2017.

20 Rehm J, Manthey J, Lange S, et al. Alcohol control policy and changes in alcohol-related traffic harm. Addiction 2020;115:655-65.

21 Penfold RB, Zhang F. Use of interrupted time series analysis in evaluating health care quality improvements. Acad Pediatr 2013;13:S38-44.

22 Spoelman WA, Bonten TN, de Waal MWM, et al. Effect of an evidence-based website on healthcare usage: an interrupted timeseries study. BMJ Open 2016;6:e013166.

23 Rehm J, Roerecke M. Reduction of drinking in problem drinkers and all-cause mortality. Alcohol Alcohol 2013;48:509-13.

24 Leicester A. How might in-home scanner technology be used in budget surveys? IFS working paper W12/01, 2012.

25 Giles L, Robinson M. Monitoring and evaluating Scotland's alcohol strategy: monitoring report 2019. Edinburgh: NHS Health Scotland, 2019. http://www.healthscotland.scot/publications/mesasmonitoring-report-2019

26 Department of Health. Responsibility deal alcohol network: pledge to remove 1 billion units of alcohol from the market by end 2015. First interim monitoring report. London: DoH, 2014. www.gov.uk/government/ uploads/system/uploads/attachment_data/file/306529/RDAN___Unit_ Reduction_Pledge_-_1st_interim_monitoring_report.pdf

27 Holmes J, Angus C, Meier PS. UK alcohol industry's "billion units pledge": interim evaluation flawed. Br Med J 2015;350:h1301. 